Jurnal Teknik Komputer AMIK BSI

Volume VI No.1 Januari 2020

P-ISSN 2442-2436, E-ISSN: 2550-0120

Akreditasi Ristekdikti, No: 21/E/KPT/2018

DOI: $10.31294 /$ jtk.v4i2

\title{
Desain Perancangan Alat Guna Pemberi Informasi Kebocoran Gas Metode Fuzzy Melalui SMS Gateway Berbasis Arduino Uno
}

\author{
Ahmad Fauzi ${ }^{1}$, Andry Maulana ${ }^{2}$, Rian Septian Anwar ${ }^{3}$ \\ ${ }^{1}$ STMIK Nusa Mandiri/Sistem Informasi \\ e-mail: ahmad.azy@nusamandiri.ac.id \\ ${ }^{2}$ STMIK Nusa Mandiri/Sistem Informasi \\ e-mail: andry.ayz@nusamandiri.ac.id \\ ${ }^{3}$ Universitas Bina Sarana Informatika \\ e-mail: rian.ptn@bsi.ac.id

\begin{tabular}{ccc}
\hline Diterima & Direvisi & Disetujui \\
$04-10-2019$ & $09-12-2019$ & $08-01-2019$ \\
\hline
\end{tabular}

\begin{abstract}
Abstrak - Sumber daya alam yang bermanfaat bagi kehidupan manusia sangat banyak tersedia di muka bumi ini, salah satu pengolahan sumber daya alam berupa gas yaitu LPG Gas. Peran gas LPG saat ini sangat penting bagi kehidupan manusia baik di rumah tangga maupun di industri. Ledakan aktual atau kebocoran gas dapat dihindari dengan sistem keamanan dan peringatan dini. Dalam Tugas Akhir ini penulis melakukan perancangan dan pembuatan sensor pendeteksi gas menggunakan sensor Arduino Uno MQ-5. Akan ada peringatan melalui pesan singkat ketika kondisi gas terdeteksi oleh sensor, alat ini akan mengirim pesan ke ponsel pengguna bahwa ada kebocoran gas. Berdasarkan hasil pengujian, alat ini mampu mendeteksi kebocoran gas LPG di sebuah ruangan, tetapi juga mampu mengirim sms yang berisi peringatan kebocoran gas ke pengguna alat tersebut. Sebagai peringatan telah terjadi kebocoran gas di kamar atau rumah pengguna gas. Dengan terciptanya alat ini, proses pemantauan tabung LPG dapat dilakukan dengan mudah dan aman. Dan alat ini dapat dikembangkan lagi menggunakan notifikasi berbasis internet.
\end{abstract}

Kata Kunci : Alat, Deteksi, Kebocoran gas

\begin{abstract}
Natural resources that are beneficial to human life are very much available in this earth, one of the processing of natural resources in the form of gas that is LPG Gas. The role of LPG gas at this time is very important for human life both in the household and in industry. Actual explosion or gas leak can be avoided with a security system and early warning. In this Final Project the authors do the design and manufacture of a gas detector sensor using Arduino Uno MQ-5 sensor. There will be a warning via a short message when the gas condition is detected by the sensor, this tool will send a message to the user's mobile phone that there is a gas leak. Based on the test results, this tool is able to detect LPG gas leak in a room, but it is also capable of sending an sms containing gas leak warning to the user of the tool. As a warning there has been a gas leak in the room or home of the gas user. With the creation of this tool, LPG tube monitoring process can be done easily and safely. And this tool can be developed again using internet-based notifications.

Keywords: tool, Detection, gas leak
\end{abstract}

\section{PENDAHULUAN}

Perkembangan ilmu pengetahuan dan teknologi yang cukup pesat bermula dari sebuah computer kecil yang disebut dengan mikrokontroller menurut (Wahyudi et al., 2019) berdampak pada meningkatnya kebutuhan manusia akan sumber daya energi. Dimana selama ini lebih banyak menggunakan sumber energi yang dihasilkan oleh alam sebagai sumber energi utama. Melalui sumber energi inilah manusia menggunakannya untuk keperluan sehari-hari, termasuk penggunaan LPG (Liquefied Petroleum Gas).

Pada Penelitian sebelumya menurut (Picfa et al., 2018) Bahwa dengan menggunakan Mikrokontroller
Atmega 16 dengan sensor GH-312

mampu mendeteksi adanya GAS LPG dan output yang dikelarkan hanya berupa buzzer suara bila terdampak adanya deteksi sebuah gas.

Pada Penelitian selanjutnya (Ramadhan et al., 2017) didapatkan pengujian kebocoran gas secara real time dan disajikan dalam bentuk tampilan Data pada layer LCD 16x2 akan terbaca sebuah text adanya kebocoran sebuah gas, bilamana terdapat terdeteksi sebuah gas.

Sedangkan pada penelitan kali ini penulis ingin menggunakan layanan SMS untuk menginformasikan bilamana terdapat sebuah kebocoran GAS LPG pada sebuah rumah tertentu, sehingga informasi yang diberikan akan langsung 
dikirimkan melalui pesan singkat SMS.

Menurut (Hakim \& Yonatan, 2017) Selain digunakan untuk keperluan dapur, LPG juga bisa digunakan sebagai bahan bakar kendaraan bermotor atau yang biasa disebut BBG (Bahan Bakar Gas). Bahkan menurut CNN Indonesia, pada tahun 2015 saja Pertamina melakukan impor 4,2 metrik ton LPG. Hal ini terkait dengan konsumsi masyarakat Indonesia terhadap penggunaan gas LPG.

Namun dari banyak kelebihan yang bisa didapatkan dari pemanfaatan LPG, ada juga beberapa faktor berbahaya yang perlu diperhatikan. Seperti proses pemasangan tabung LPG yang tidak benar dapat menyebabkan terjadinya kebocoran gas yang nantinya dapat memicu ledakan. Untuk itulah diperlukan alat yang dapat mendeteksi kebocoran gas dan memberikan notifikasi yang cepat supaya bisa dilakukan penanggulangan dini.

Banyak rumah atau pun ruko (rumah toko) yang sudah mereka bangun tidak dilengkapi dengan sistem pemantauan kebocoran gas LPG. Padahal jika terjadi kebocoran gas hal ini akan sangat berbahaya karena dapat menyulut terjadinya kebakaran.

\section{METODOLOGI PENELITIAN}

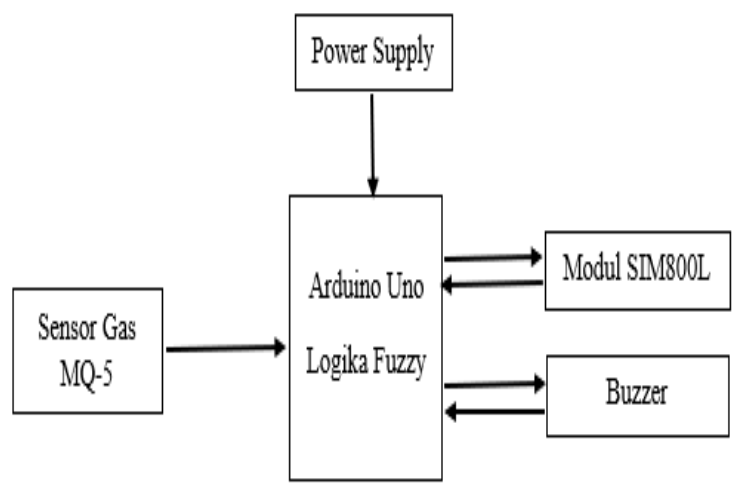

Gambar 1. Penerapan Logika Fuzzy

Sumber: Rancangan Penulis

(Ramadhan et al., 2017) Pada Alat pendeteksi gas tersebut menggunakan sensor Gas Seri MQ-5 yang mampu mengetahui jenis gas LPG dan untuk prosesnya makan diperlukan sebuah system minimum yang membutuhkan power atau catu daya untuk menghidupkan hardware yang terdapat pada Arduino, pada system mininun Arduino terdapat sebuah logika untuk menentukan hasil dari yang ditangkap oleh sensor MQ-5 dengan menggunakan metode Fuzzy.

Sedangkan pada proses pengolahan logika Fuzzy terdapat beberapa sub diantaranya:

1. Fuzzifikasi

2. Inferensi

3. Defuzzifikasi

Masing-masing proses memiliki keterkaitan antar satu sama selain sehingga dapat menghasilkan output akhir berupa buzzer dan pengiriman data melalui sms gateway, dan berikut adalah flowchart control fuzzy

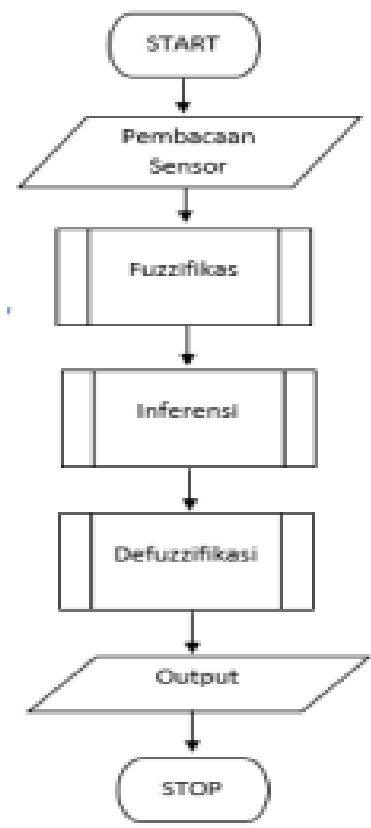

Gambar 2. Flowchar Logika Fuzzy

Sumber: Rancangan Penulis

Pada Fuzzifikasi terjadi proses input data yang berupa nilai pasti, system yang dibangun memiliki dapa inputan berupa data kadar gas yamg terdeteksi oleh sensnor MQ-5 .

Setelah proses Fuzzifikasi maka ketahap selanjutnya yaitu tahap inferensi dimana pada proses ini terdapat penggabungan data yang sudah ditetapkan pada proses fuzzifikasi yang terbentuk atas 3 himpunan fuzzy sebagai input yaitu: kadar gas rendah, kadar gas tinggi dan Kondisi gas bocor.

Pada aturan fuzzy tersbut akan memberikan sebuat instruksi dalam fuzzy perintah yang dibuat menggunakan perintah "if", "then" dan "and"aturan dasar fuzzy kebocoran gas dapat dilihat dari alur pada table dibawah ini:

Tabel 1. Aturan Fuzzy

\begin{tabular}{lll}
\hline Aturan & Kadar Gas & Kodisi \\
\hline Alur0 & rendah & Normal \\
\hline Alur1 & Tinggi & Gas Bocor \\
\hline
\end{tabular}

Sumber: Rancangan Penulis

Berdasarkan dua aturan tersebut akan ditentukan nilai $\mathrm{x}$ untuk masing-masing ukuran, setelah dikatahui sebuah nilai $\mathrm{x}$ maka dapat mengevaluasi nilai sebuah alur untuk mencari nilai yang terbesar seperti:

1. Variable kondisi normal yang terdiri dari alur0

2. Variable kondisi gas bocor yang terdiri dari alur1 


\section{HASIL DAN PEMBAHASAN}

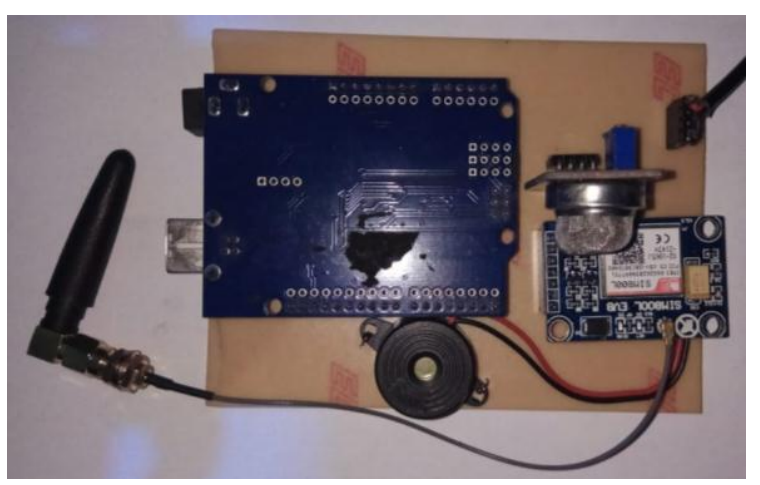

Gambar 3. Perancngan Alat

Sumber: Rancangan Penulis

Source Code untuk konfigurasinya adalah sebagai berikut:

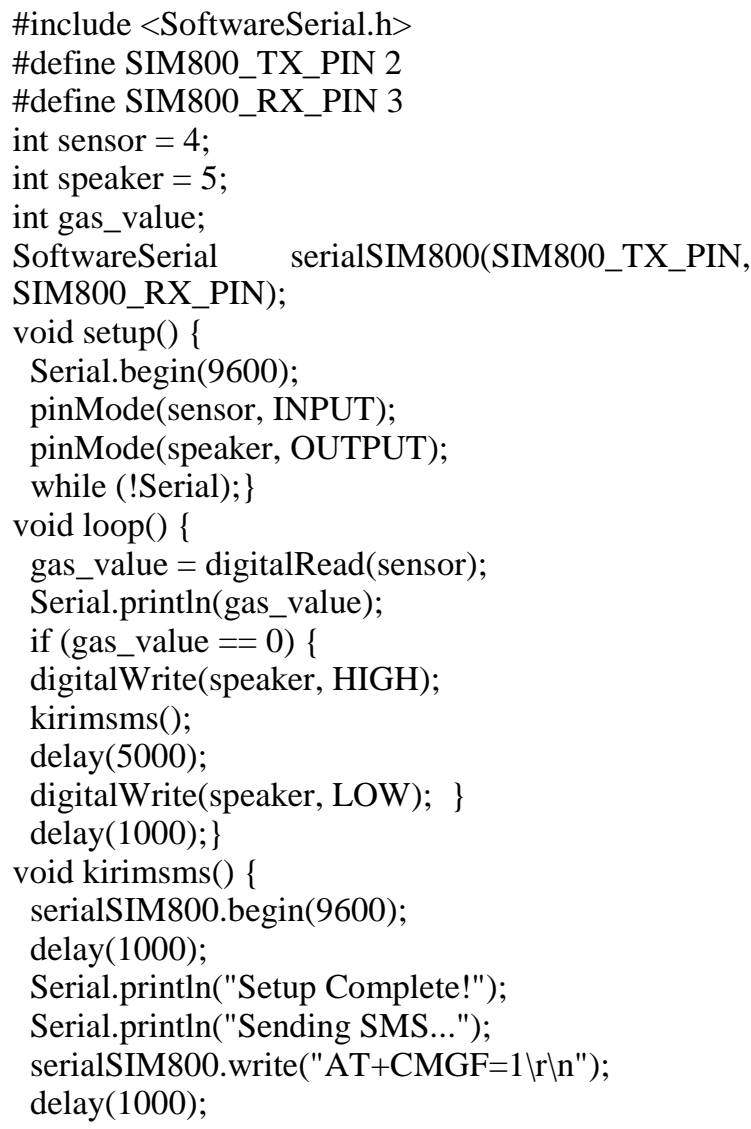

Dengan menggunakan adaptor sebesar $12 \mathrm{~V}$ maka Sistem Minimum berbasis arduino uno mendapatkan sumber tegangan arus DC lalu terhubung dengan sensor gas MQ-5 pada system minimum sebagai Input pendeteksi adanya Gas LPG lalu untuk proses output terdapat 2 device keluaran, yang pertama adalah device buzzer dimana komponen ini sudah terhubung dengan system minimum yang akan mengeluarkan suara buzzer sebagai tanda bahwa sensor menangkap kadar gas LPG diudara dan outpu kedua adalah adanya device ModuleSIM800L yang digunakan untuk mengirimkan pesan singkat atau SMS kepada nomer yang sudah dikonfigurasi dengan menggunakan jaringan GSM

Untuk mengetahui proses pembuatan alat dilakukan beberapa kali percobaan.

1. Hasil Input

Tabel 2. Percobaan input

\begin{tabular}{llll}
\hline No & Percobaan & Ampere & \multicolumn{2}{c}{ Hasil } \\
\hline 1. & Pertama & Adaptor 1 A. & $\begin{array}{l}\text { Alat tidak } \\
\text { berfungsi }\end{array}$ \\
\hline 2. & Kedua & Adaptor 1,5 A & Alat tidak stabil \\
\hline 3. & Ketiga & Adaptor 2 A & $\begin{array}{l}\text { Alat berfungsi } \\
\text { dengan baik }\end{array}$ \\
\hline 4. & Keempat & Adaptor 2,5 A & $\begin{array}{l}\text { Alat berfungsi } \\
\text { tidak optimal }\end{array}$ \\
\hline Sumber: Hasil Penelitian & \\
\hline
\end{tabular}

Percobaan pertama menggunakan Arus 1A alat tidak berfungsi, Percobaan kedua ditambahkan Arus menjadi 1,5A, alat masih tidak berfungsi, Percobaan ketiga ditambah lagi Arus menjadi 2A, alat berfungsi dengan baik, Percobaan terakhir/keempat Arus ditambahkan menjadi 2,5A alat tidak berfungsi secara Optimal

Setelah beberapa kali melakukan percobaan dapat di ambil kesimpulan, alat berfungsi dengan baik dengan menggunakan Adaptor 2A lebih/kurang dari $2 \mathrm{~A}$ alat tidak akan berfungsi/Rusak.

2. Hasil Output

Untuk mengetahui hasil dari output alat, dilakukan percobaan terhadap Handphone yang bertugas menampilkan hasil Notifikasi yang melewati sensor.

Tabel 3. Percobaan Output

\begin{tabular}{llll}
\hline No & \multicolumn{1}{c}{ Gas } & Sensor & HP (notifikasi) \\
\hline $\mathbf{1}$ & Percobaan & Terbaca & Terkirim \\
& pertama & & Notifikasi \\
\hline $\mathbf{2}$ & Percobaan & Terbaca & Terkirim \\
& kedua & & Notifikasi \\
\hline
\end{tabular}




\begin{tabular}{llll}
\hline 3 & Percobaan & Tidak & Tidak Terkirim \\
& ketiga & Terbaca & Notifikasi
\end{tabular}

Sumber: Hasil Penelitian

Pada percobaan pertama pada jarak $3 \mathrm{~cm}$ sensor mendeteksi adanya gas, Pada percobaan kedua pada jarak $6 \mathrm{~cm}$ sensor mendeteksi adanya gas, Pada percobaan ketiga pada jarak $9 \mathrm{~cm}$ sensor tidak mendeteksi adanya gas

Dari percobaan diatas dapat disimpulkan sensor hanya mendeteksi gas pada jarak 1-6cm lebih dari itu sensor tidak dapat membaca adanya gas.

Secara keseluruan alat dapat berfungsi dengan baik, Gas yang melewati sensor dapat di baca oleh sensor, meski memang tidak seratus persen berhasil namun persentasi keberhasilan lebih tinggi seperti yang tertera pada pengamatan di atas. Hp yang menampilkan Notifikasi yang berhasil terbaca oleh sensor serta bunyi alarm yang di hasilkan oleh buzzer untuk memberi peringatan orang sekitar yang memakai alat pendeteksi gas bocor bahwa telah terjadi kebocoran gas.

\section{KESIMPULAN}

Berdasarkan dari pembahasan dan pengujian alat dari bab sebelumnya,

dapat diambil kesimpulan sebagai berikut:

1. Dengan menggunakan Software dan dikoneksikan dengan Mikrokontroler Arduino yang dirancang menggunakan sensor MQ-5 dapat mendeteksi Gas LPG.

2. Dengan menggunakan teknologi SMS dan Bunyi dari Buzzer, sistem dapat memberikan informasi secara realtime kepada pengguna dan orang yang disekitar alat tersebut.

3. Tindakan dini yang dilakukan pengguna dapat meminimalisir terjadinya bahaya kebocoran Gas yang bisa menyebabkan kebakaran akibat terlambatnya penanganan dini kebocoran tabung Gas LPG.

\section{REFERENSI}

Hakim, L., \& Yonatan, V. (2017). Deteksi Kebocoran Gas LPG menggunakan Detektor Arduino dengan algoritma Fuzzy Logic Mandani. Jurnal RESTI (Rekayasa Sistem Dan Teknologi Informasi), 1(2), 114. https://doi.org/10.29207/resti.v1i2.35

Picfa, M., Aji, H., \& Kautsar, A. (2018).
Perancangan Alat Pendeteksi Kebocoran Gas Berbasis. IV(2), 105-112.

Ramadhan, L. I., Syauqy, D., \& Prasetio, B. H. (2017). Sistem Pendeteksi Kebocoran Gas LPG Menggunakan Metode Fuzzy yang Diimplementasikan dengan Real Time Operating System ( RTOS ). Jurnal Pengembangan Teknologi Informasi Dan Ilmu Komputer (J-PTIIK) Universitas Brawijaya, 1(11), 1206-1213.

Wahyudi, I., Bahri, S., \& Handayani, P. (2019). Aplikasi Pembelajaran Pengenalan Budaya Indonesia. $\quad V(1), \quad 135-138$. https://doi.org/10.31294/jtk.v4i2 